\title{
Overweight among children and adolescent with type I diabetes mellitus: prevalence and associated factors
}

\author{
Verônica Medeiros da Costa ${ }^{1}$, Patricia de Carvalho Padilha ${ }^{1,2,3^{*}}$, Géssica Castor Fontes de Lima ${ }^{1,3}$, \\ Aline Alves Ferreira ${ }^{4}$, Jorge Luiz Luescher ${ }^{1}$, Luciana Porto ${ }^{1}$ and Wilza Arantes Ferreira Peres ${ }^{2,5}$
}

\begin{abstract}
Objectives: Describe the overweight frequency (overweight and obesity) and identify the factors associated with this in children and adolescents with type 1 diabetes mellitus (T1DM) treated at a University Children's Hospital in Rio de Janeiro.

Methods: This is an analytical cross-sectional study, which included patients diagnosed with T1DM who had complete anthropometric data (weight and height) and excluded those using drugs with effect on weight gain, genetic syndromes, celiac disease, hypothyroidism, renal failure and other chronic diseases, and pregnant women. The data collection was referring to the last consultation, and with respect to laboratory tests, the most recent data was collected. The dependent variable was the overweight, defined as $Z$ score $\geq 1$. The independent variables were gender, age, insulin dose, duration of disease, lipid profile, glycated hemoglobin, type of prescribed food planning, and place of residence. A logistic regression model was built for each outcome studied, considering significant associations those with $p<0.05$.
\end{abstract}

Results: The study included 195 patients with a mean age of $10.6( \pm 3.8)$ years, and $49.7 \%(n=97)$ aged less than 10 years. The overweight frequency was $40 \%(n=78)$. The age $\geq 10$ years $(O R 0.41 ; 95 \% \mathrm{Cl} 0.20-0.86 ; p=0.019)$ and the dose of insulin/kg ideal weight (OR 3.38; $95 \% \mathrm{Cl}$ 1:55-7:39; $p=0.002$ ) were considered the variables associated with overweight.

Conclusions: There was a high prevalence of overweight, which explains strategies for promoting healthy eating habits and changing lifestyle with a focus on children and adolescents with diabetes.

Keywords: Nutritional assessment, Type 1 diabetes mellitus, Children, Adolescents, Overweight

\section{Background}

Historically, due to acute lack of insulin production, type 1 diabetes mellitus (T1DM) was associated with severe emaciation diagnosis. However, with the worldwide overweight epidemic in recent decades, there was an increase in the incidence of type 2 diabetes mellitus (T2DM), especially in adolescents, making it as common as type 1 in this age group in some countries $[1,2]$.

\footnotetext{
*Correspondence: paticpadilha@yahoo.com.br

${ }^{2}$ Department of Nutrition and Dietetics, Instituto de Nutrição Josué de Castro (INJC/UFRJ), Rio de Janeiro-RJ, Brazil

Full list of author information is available at the end of the article
}

Consequently, there were also changes in the nutritional status of children and adolescents with T1DM, which may be overweight at the beginning, hindering the differential diagnosis between the two types of diabetes 1.

In a cohort study conducted in the United States, with children and adolescents with type 1 diabetes, a prevalence of $38.5 \%$ of overweight was found, showing that the prevalence of overweight and obesity in children and adolescents with type 1 diabetes is increasing as in the general population [3]. Another American study called SEARCH found a prevalence of overweight of $34 \%$ among young people with type 1 diabetes, not differing from non-diabetic population of the same age [4]. 
These data corroborate the global trend of increase of overweight in children, including the diabetic population, as evidenced by Libman et al. [5] who observed a threefold increase in the prevalence of overweight in two consecutive decades. Certainly, the presence of overweight is noteworthy since in addition to increasing cardiovascular risk, it increases insulin resistance, which can intensify complications in the short and long term, influencing the diabetes treatment [4].

In patients with type 1 diabetes, the risk factors for developing cardiovascular diseases begin in childhood and can persist into adulthood. Studies have shown the early onset of severe atherosclerosis in children with type 1 diabetes compared to healthy children due to damage caused by high blood glucose [6,7].

It is believed that excess weight can be explained by high doses of insulin, lifestyle changes, especially those related to food intake and reducing energy expenditure, and high levels of growth hormone [8,9]. Moreover, recent evidence highlights that overweight is not associated only with T2DM, because patients with T1DM may also have insulin resistance $[9,10]$.

Modern therapies with flexible schemes of insulin therapy resulted in less restrictive diet, which can represent less healthy food choices $[11,12]$. Therefore, young people with T1DM should be advised about the conscious use of the method $[13,14]$.

Given the above, the objective of this study was to describe the frequency of overweight (overweight and obesity) and identify the factors associated with this in children and adolescents with type 1 diabetes treated at the Pediatric University Hospital of Rio de Janeiro.

\section{Methods}

This is an analytical cross-sectional study based on retrospective data of children and adolescents diagnosed with T1DM assisted in the Diabetes Clinic of a University Children's Hospital in the city of Rio de Janeiro. That clinic is reference center for the treatment of children and adolescents with diabetes in the city of Rio de Janeiro, consisting of a multidisciplinary team of pediatric endocrinologists, nutritionists, nurses, social workers and psychologists.

The study included all patients enrolled in the clinic database between April 2009 and December 2011, diagnosed with T1DM and complete anthropometric data (weight and height) recorded in the database, and excluded those users of drugs with effect on weight gain, genetic syndromes, celiac disease, hypothyroidism, renal failure, or other chronic diseases, pregnant women and patients with incomplete anthropometric information.

For the nutritional status diagnosis, the body mass index (BMI) was used, as recommended by the World
Health Organization $[15,16]$ and adopted by the Ministry of Health [17]. For the statistical analysis, were created the without overweight variable (low weight and eutrophia) and the overweight variable (overweight and obesity).

The data collection was referring to the last consultation, and with respect to laboratory tests, the most recent data was collected, which according to the routine they are requested between consultations. The laboratory tests that were used in the analysis were the following: HbA1c and lipid profile (total cholesterol, low density lipoprotein (LDL), high density lipoprotein (HDL) and triglycerides). The HbA1c was measured by the high efficiency liquid chromatography method (HELC), and classified according to the recommendation by the American Diabetes Association [18] as adequate (HbAC1 < $7.5 \%$ ) and inadequate $(\mathrm{HbAC} 1 \geq 7.5 \%)$. The lipid profile classification used was: total cholesterol (desirable if $<150 \mathrm{mg}$ / $\mathrm{dL}$, borderline if between 150 and $169 \mathrm{mg} / \mathrm{dl}$, increased if $\geq 170 \mathrm{mg} / \mathrm{dL}$ ), HDL (desirable if $\geq 45 \mathrm{mg} / \mathrm{dL}$, inadequate if $<45 \mathrm{mg} / \mathrm{dL}$ ), LDL (desirable if $<100 \mathrm{mg} / \mathrm{dL}$, borderline if between 100 and $129 \mathrm{mg} / \mathrm{dl}$, increased if $\geq 130 \mathrm{mg} / \mathrm{dL}$ ), and triglycerides (desirable if $<100 \mathrm{mg} / \mathrm{dL}$, borderline if between 100 and $129 \mathrm{mg} / \mathrm{dL}$, and increased if $\geq 130 \mathrm{mg} /$ dL) [19]. However, a variable categorized as presence (at least one lipid abnormality) or absence of dyslipidemia was created.

The dependent variable in the study was overweight (overweight-BMI between 1 and $2 \mathrm{Z}$ score and Obesity $\mathrm{BMI}>2 \mathrm{Z}$ score). The independent variables were: clinical characteristics (HbA1c, dyslipidemia, disease durationmore than 5 years and less than 5 years, and insulin dose per kg/ideal weight); diet (type of prescribed meal plantraditional method of portions and carbohydrate counting method $(\mathrm{CCHO})$, and sociodemographic (place of residence-Rio de Janeiro and adjacent regions, and age $<10$ years and $\geq 10$ years, and gender).

Descriptive statistical procedures were performed. To examine the isolated effect of the independent variables in overweight, bivariate logistic regression was used. The covariates that showed a $\mathrm{p} \leq 0.20$ value, or the variables for potential explanation (which has shown an association with overweight in previous studies), were considered as candidates for remaining in the final model.

In the following analysis, the selection of the variables included in the final logistic model was performed by automated and manual procedures (Forward and Wald test). The interaction of the variables was verified by the correlation matrix.

The selection of the final model took into account the analysis of residues by graphical observation, deviance analysis, statistics and akaike information criteria (AIC), as well as clinical and epidemiological significance. We 
used the $95 \%$ significance level for the estimated calculation of odds ratio (OR) in binary logistic regression.

The descriptive statistical analysis were performed with SPSS software for Windows version 21.0 (SPSS Inc. Chicago, USA) and the others ones in the free software R, version 3.0.1, using the epicalc library.

The study was designed respecting the expected ethical aspects. It was approved by the Research Ethics Committee of the institution under protocol number 59/11.

\section{Results}

The sample was composed of 195 children and adolescents, of whom 106 (54.4\%) males and 89 (45.6\%) females. The mean age was $10.6( \pm 3.8)$ years, $49.7 \%$ $(n=97)$ aged less than 10 years. The classification of the nutritional state of the sample is shown in Fig. 1, with $1.0 \%(\mathrm{n}=2)$ with low weight, $59 \%(\mathrm{n}=115)$ eutrophy, $30.3 \%(\mathrm{n}=59)$ with overweight, and $9.7 \%(\mathrm{n}=19)$ with obesity, totaling $40 \%(n=78)$ with excess weight.

As for HbA1C, 181 individuals had this data, and $49.2 \%$ $(\mathrm{n}=89)$ were adequate compared to the values proposed as ideal, and the average Hb1Ac $8.07 \%$. The age at diagnosis, disease duration and dose of insulin $/ \mathrm{kg}$ of ideal weight had averages of $5.54( \pm 2.79)$ years, $5.58( \pm 3.37)$ years, and $1.03( \pm 0.48)$ units, respectively. In Table 1, the average values of total cholesterol, LDL, HDL and triglycerides are represented. Regarding the lipid profile, $42.8 \%$ $(\mathrm{n}=71)$ had high total cholesterol, $15.8 \%(\mathrm{n}=26)$ had inadequate HDL, $28.5 \%(\mathrm{n}=47)$ and $12.5 \%(\mathrm{n}=20)$ had LDL-c and elevated triglycerides, respectively, and $71.5 \%$ $(n=125)$ had some change in the lipid profile.

The dietary planning based on $\mathrm{CCHO}$ was followed by $44.7 \%(\mathrm{n}=85)$, and the method of portions by $55.3 \%$ of the patients $(\mathrm{n}=105)$. In the evaluation of the place of residence, it was found that the majority $68 \%(n=132)$ lived in the city of Rio de Janeiro.

The logistic regression models, unadjusted and adjusted for factors associated with overweight are shown in Tables 2 and 3, respectively. After adjusting the variables, the age $\geq 10$ years was protective, and the higher dose of insulin $/ \mathrm{kg}$ ideal weight increased the chance for
Table 1 Average values of total cholesterol, LDL-C, HDL-C and triglycerides in children and adolescents with T1DM treated at a University Children's Hospital in Rio de Janeiro

\begin{tabular}{lcclcr}
\hline Lipid fraction & $\mathbf{n}$ & Minimum & Maximum & Average & SD \\
\hline $\mathrm{TC}(\mathrm{mg} / \mathrm{dL})$ & 166 & 107 & 284 & 167.92 & 33.53 \\
$\mathrm{LDL}-\mathrm{c}(\mathrm{mg} / \mathrm{dL})$ & 165 & 42 & 197 & 87.04 & 27.98 \\
$\mathrm{HDL}-\mathrm{c}(\mathrm{mg} / \mathrm{dL})$ & 165 & 29 & 196 & 64.4 & 22.90 \\
$\mathrm{TG}(\mathrm{mg} / \mathrm{dL})$ & 160 & 30 & 287 & 78.38 & 049.43 \\
\hline
\end{tabular}

$C T$ total cholesterol; $L D L-C$ low density lipoprotein; $H D L-C$ high density lipoprotein; TG triglycerides; SD standard deviation

the overweight. The protection related to age $\geq 10$ years is represented by OR 0.41 , which showed a relative risk lower than half for present overweight, when compared to age lower than 10 years. In contrast, higher doses of insulin increased more than three times the relative risk for overweight, when compared to the lowest dose of insulin $/ \mathrm{kg}$ ideal weight.

\section{Discussion}

The prevalence of overweight is high and confirms data from national and international studies. It is believed that the nutritional status of children and adolescents with T1DM reflects the results of the data found in the Brazilian population without T1DM at the same age, characterized by the representative increase of overweight with continuous reduction of the prevalence of malnutrition [20].

Luczynski et al. [21] in a sample of 500 Polish children with T1DM, found a prevalence of $30.2 \%$ of overweight, $3.2 \%$ of the metabolic syndrome and $4.8 \%$ of hypertension. In Brazil, Liberatore et al. [1] and Marques et al. [8] found among children and adolescents with type 1 diabetes prevalence of overweight of 16 and $14.1 \%$, respectively. These studies differ due to the smaller sample size, period and criteria adopted for anthropometric assessment.

More recently, a large multicenter study in 28 public clinics in 20 Brazilian cities, identified an overweight

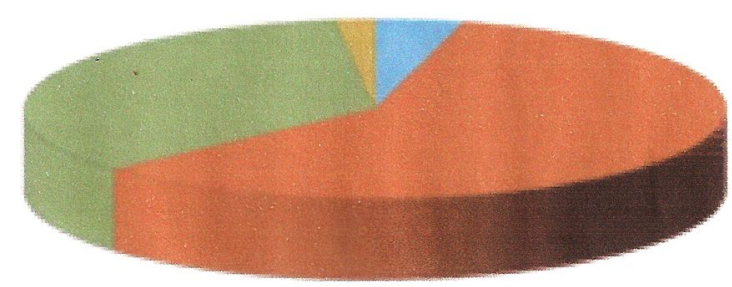

Low weight

Eutrophic

Overweight

Obesity

Fig. 1 Nutritional status classification of children and adolescents with type 1 diabetes: low weight $1 \%(n=2)$, eutrophic $59 \%(n=115), 30.3 \%$ overweight $(n=59)$ and obesity $9.7 \%(n=19)$ 
Table 2 Prevalence and unadjusted odds ratios of the factors associated with overweight in children and adolescents in a University Children's Hospital in Rio de Janeiro

\begin{tabular}{lcccc}
\hline Variables & $\mathbf{n}$ & OR & RI 95 \% & P \\
\hline Age (years) & & & & \\
$<10$ & 42 & 1 & & \\
$\geq 10$ & 36 & 0.76 & $0.43-1.35$ & 0.326 \\
Gender & & & & \\
Male & 35 & 1 & & 0.044 \\
Female & 42 & 1.81 & $1.01-3.24$ & \\
Place of residence & & & & \\
Rio de Janeiro & 50 & 1 & & \\
Surroundings & 26 & 1.18 & $0.64-2.19$ & 0.589 \\
$\begin{array}{l}\text { Disease duration (years) } \\
<5\end{array}$ & 37 & 1 & & \\
$>5$ & 39 & 0.92 & $0.51-1.64$ & 0.772 \\
Dietary planning methods & & & & \\
Portions & 40 & 1 & & \\
CCHO & 35 & 1.14 & $0.63-2.04$ & 0.666 \\
HbA1C adequacy & & & & \\
Adequate & 30 & 1 & & 0.102 \\
Inadequate & 42 & 1.65 & $0.9-3.01$ & \\
Daily dose of insulin/kg & - & 2.12 & $1.13-3.97$ & 0.019 \\
Changes in lipid profile & & & & \\
No & 12 & 1 & & \\
Yes & 50 & 1.61 & $0.75-3.45$ & \\
\hline
\end{tabular}

Table 3 Odds ratio adjusted for factors associated with overweight in children and adolescents treated at the Paediatric University Hospital of Rio de Janeiro

\begin{tabular}{llll}
\hline Variables & OR & RI 95 \% & P \\
\hline Age (years) & & & \\
$<10$ & 1 & & \\
$\geq 10$ & 0.41 & $0.20-0.86$ & 0.019 \\
Daily dose of insuln/kg & & & \\
\hline
\end{tabular}

AIC akaike information criterion: 252.81

a Daily dose of insulin per kilogram of ideal body weight

prevalence of $31.6 \%$ among individuals with T1DM, being mostly in the age group up to 15 years. These data are consistent with the Household Budget Survey [22], where $33.5 \%$ of children aged 5-10 years were found to be overweight, while the prevalence among adolescents was $21.5 \%$. Thus, it is observed that children and adolescents with T1DM are following the epidemiological profile of overweight shown by children and adolescents without diabetes.

Noteworthy is the high frequency of dyslipidemia, consistent with findings in literature. The frequency of elevated LDL ( $>100 \mathrm{mg} / \mathrm{dL}$ ) in other studies ranges from 20 to $50 \%[4,23]$. However, the literature is poor in relation to information on the absorption and synthesis of cholesterol in T1DM. Also, it is not known the actual prevalence of dyslipidemia in children and adolescents with this disease, which hinders the study of demographics, social-economics or ethnic factors associated with it. Alves et al. reported that $32.6 \%(n=49)$ children and adolescents with T1DM and mean HbA1c of $11 \%$ had some form of dyslipidemia [23].

The disease duration variable of disease was not associated with overweight. However, Jose et al. [24] found association between disease duration and insulin doses with worse control of T1DM according to the value of HbA1c. This lack of association between disease duration and overweight is justified; patients with the disease for a longer period of time and adolescents know the symptoms and can manage insulin better, so they tend to subtract insulin doses and/or meals as measures to prevent undesirable weight gain.

Age $\geq 10$ years was protective to overweight when compared to age $<10$ years, possibly because at the lower age range there is a greater fear from parents regarding the episodes of hypoglycemia, which leads them to overfeed these children as prevention. On the other hand, the greater insulin dose was associated with overweight, which confirms the literature. These results justify further specific actions aimed to younger patients' family members and overweight patients because they have higher risks of overweight and large doses of insulin, respectively, resulting in insulin resistance and increased risk of future complications.

Reinehr et al. [10], in a study including 8156 children and adolescents with type 1 diabetes on intensive insulin therapy, found a positive association between overweight and the daily dose of insulin per kilogram of ideal weight, which would explain the insulin resistance in this group with T1DM [10]. However, Liberatore et al. showed no association between the dose of insulin and BMI [1].

From a physiological point of view, insulin sensitivity must be related to lean body mass, since glucose intake occurs predominantly in muscle tissue. The diabetic patients that are overweight often require higher doses of insulin, since the glucose intake occurs about $75 \%$ in the muscle tissue and only $4 \%$ in the fat tissue $[1,10]$.

Because insulin is the key to the entry of glucose into the cell, a greater insulin demand occurs to perform this functionin the subjects with excess of fat tissue. This process relates to lower glucose intake and consequent increased demand for insulin, suggesting that the higher the fat mass, the higher the insulin resistance.

Fröhlich-Reiterer et al. [25] identified the predictor factors for BMI increase during the course of diabetes. 
For females, low BMI in early diabetes, intensive insulin therapy, and higher insulin dose, additionally to longer disease duration and age were associated with greater increases in BMI.

The same authors suggest that the number of injections, the amount and type of insulin, are determining factors for increased BMI. The reasons for this are probably the anabolic effect of insulin, which promotes weight gain, stimulating the lipogenesis, inhibiting protein catabolism and slowing basal metabolism, on one hand, and on the other hand, the weight gain is influenced by the caloric intake.

Children with intensive insulin therapy are likely to have a more flexible eating pattern, which could lead to increased risk of overweight. However, our study showed no association between the type of diet planning and overweight. This fact may be due to the approach taken in the $\mathrm{CCHO}$ prescription, which emphasizes the consumption of healthy foods, regardless of the dietary planning method. In addition, studies on nutrition in T1DM are scarce, but studies have shown that weight gain can also be influenced by diets high in fat and lower carbohydrate content to try to avoid insulin injections [26, 27].

An American study, with 35 young people between 8 and 21 years, with T1DM, showed that insulin regimens and more flexible diets are associated, according to parents and children, to frequent consumption of unhealthy foods such as high calories, low in fiber and micronutrients snacks [28]. In Brazil, an epidemiological study conducted about diet adherence, cardiovascular risk and T1DM reported that only $54.2 \%$ of patients adhered to the diet prescribed, and those with better adherence had lower BMI, improved metabolic control (HbA1C and lipid profile), and best pressure level. The study also found lower adherence among those with high BMI [29].

We can cite as limitations of this study the absence of anthropometric measurements, such as waist circumference, measures of body composition and level of physical activity, and for not being a longitudinal study, which would allow the assessment of the evolution of anthropometric profile and its relation to the factors studied during the treatment.

\section{Conclusions}

The increase in prevalence of risk factors associated with overweight among children and adolescents is a global health problem. As children and adolescents with type 1 diabetes have also the same risk of developing overweight, monitoring weight gain is an important aspect in the care of children and adolescents with T1DM. Especially among those of younger age and with higher doses of insulin. In this context, it is necessary to discuss strategies for promoting glycemic control in this group, especially in the group of children under 10 years, with a focus on lifestyle, which emphasizes the promotion of healthy eating habits and physical activity.

\section{Abbreviations \\ T1DM: type 1 diabetes mellitus; T2DM: type 2 diabetes mellitus; BMI: body mass index; LDL: low density lipoprotein; HDL: high density lipoprotein; HbAC1: glycated hemoglobin; HELC: high efficiency liquid chromatography; CCHO: carbohydrate counting method; AIC: akaike information criteria.}

\section{Authors' contributions}

VMC, PCP and WAFP participated in the design and planning of the study, in data collection, critical analysis of the results, in the preparation and review of the final manuscript. GCFL, AAF, JLL and LP participated in data collection, analysis of results and preparation of drafts the manuscript. All authors read and approved the final manuscript.

\section{Author details}

${ }^{1}$ Diabetes Sector of the Instituto de Puericultura e Pediatria Martagão Gesteira (IPPMG/UFRJ), Rio de Janeiro-RJ, Brazil. ${ }^{2}$ Department of Nutrition and Dietetics, Instituto de Nutrição Josué de Castro (INJC/UFRJ), Rio de Janeiro-RJ, Brazil. ${ }^{3}$ Research Group on Maternal and Child Health (GPSMI), INJC/UFRJ, Rio de Janeiro-RJ, Brazil. ${ }^{4}$ Department of Social and Applied Nutrition, INJC/UFRJ, Rio de Janeiro-RJ, Brazil. ${ }^{5}$ Hepatology Sector of the Hospital Universitário Clementino Fraga Filho (HUCFF)/UFRJ, Rio de Janeiro-RJ, Brazil.

\section{Acknowledgements}

The authors would like to thank the research support agency that sponsored the study: Fundação de Amparo a Pesquisa do Estado do Rio de Janeiro (FAPERJ) and also to the staff of Diabetes Sector for the incentive to the research.

\section{Competing interests}

The authors declare that they have no competing interests.

\section{Consent for publication}

The authors hereby declare that the article is original and that its contents have not been published in full or in part. We also would like to declare that the manuscript has been read and approved by all authors.

\section{Ethics approval and consent to participate}

The study was designed respecting the expected ethical aspects. It was approved by the Research Ethics Committee of the Institution.

\section{Funding}

Fundação de Amparo a Pesquisa do Estado do Rio de Janeiro (FAPERJ).

Received: 10 May 2016 Accepted: 23 June 2016

Published online: 16 July 2016

\section{References}

1. Liberatore RR, Cardoso-Demartin AA, Ono AHA, et al. Prevalência de obesidade em crianças e adolescentes com diabetes melito tipo 1. Rev Paul Pediatr. 2008;26:142-5.

2. Teles SAS, Fornés NS. Consumo alimentar e controle metabólico em crianças e adolescentes portadores de diabetes melito tipo1. Rev Paul Pediatr. 2011:29:378-84

3. Van Vliet M, Vander-Heyde JC, Diamant M, et al. Overweight is highly prevalent in children with type 1 diabetes and associates with cardiometabolic risk. J Pediatr. 2010;156:92330.

4. Liu LL, Lawrence JM, Davis C, et al. Prevalence of overweight and obesity in youth with diabetes in USA: the SEARCH for diabetes in youth study. Pediatr Diabetes. 2010;11:4-11. 
5. Libman IM, Pietropaolo M, Arslanain SA, et al. Changing prevalence of overweight children and adolescents at on set of insulin treated diabetes. Diabetes Care. 2003;26:2871-5.

6. Jarvisalo MJ, Jartti L, Nanto-Salonen K, et al. Increased aortic intima-media thickness: a marker of preclinical atherosclerosis in high risk children. Circulation. 2001;104:2943-7.

7. Margeirsdottir HD, Larsen JR, Brunborg C, et al. The norwegian study group for childhood diabetes high prevalence of cardiovascular risk factors in children and adolescents with type 1 diabetes: a population-based study. Diabetologia. 2008;51:554-61.

8. Marques RMB, Fornés NS, Stringhini MLF. Fatores socioeconômicos, demográficos, nutricionais e de atividade física no controle glicêmico de adolescentes portadores de diabetes melito tipo 1. Arq Bras Endocrinol Metab. 2011;55:194-202.

9. Wiegand $\mathrm{S}$, Raile K, Reinehr T, et al. Daily insulin requirement of children and adolescents with type 1 diabetes: effect of age, gender, body mass index and mode of therapy. Eur J Endocrinol. 2008;158:543-9.

10. Reinehr T, Holl RW, Roth $\mathrm{CL}$, et al. Insulin resistance in children and adolescents with type 1 diabetes mellitus: relation to obesity. Pediatr Diabetes. 2005;6:5-12

11. Metha SN, Quinn N, Volkening LK, et al. Impact of carbohydrate counting on glycemic control in children with type 1 diabetes. Diabetes Care. 2009;32:1014-6.

12. Rovner AJ, Nansel TR. Are Children With Type 1 Diabetes Consuming a Healthful Diet? Diabetes Educ. 2009;35:97-107.

13. Gellar L, Rovner AJ, Nansel RT. Whole grain and legume acceptability among youths with type1 diabetes. Diabetes Educ. 2009;35:422-7.

14. Collado-Mesa F, Barceló A, Arheart KL, et al. An ecological analysis of childhood-onset type 1 diabetes incidence and prevalence in Latin America. Rev Panam Salud Publica. 2004;15:388-94.

15. De Onis M, Onyango AW, Borghi E, et al. Development of a WHO growth reference for school-aged children and adolescents. Bull World Health Organ. 2007:85:660-7.

16. WHO Multicentre Growth Reference Study Group. WHO Child Growth Standards based on length/height, weight and age. Acta Paediatr Suppl. 2006;450:76-85

17. Brasil. Ministério da Saúde. Vigilância Alimentar e Nutricional - SISVAN. Brasília, DF: Ministério da Saúde 2008.
18. American Diabetes Association. Standards of medical care in diabetes-2015. Diabetes Care. 2015;38:S1-99.

19. Sociedade Brasileira de Cardiologia. I Diretriz de prevenção da aterosclerose na infância e na adolescência. Arq Bras Cardiol. 2005;85:3-36.

20. Brasil. Ministério do Planejamento, Orçamento e Gestão. Instituto Brasileiro de Geografia e Estatística (IBGE). Pesquisa Nacional de Saúde do Escolar (PENSE)-2009. Rio de Janeiro, RJ: IBGE, 2009.

21. Luczyński W, Szypowska A, Głowińska-Olszewska B, et al. Overweight, obesity and features of metabolic syndrome in children with diabetes treated with insulin pump therapy. Eur J Pediatr. 2011;170:891-8.

22. Brasil. Ministério do Planejamento, Orçamento e Gestão. InstitutoBrasileiro de Geografia e Estatística (IBGE). Pesquisa de Orçamentos Familiares (POF)-2008/2009: Análise do consumo alimentar pessoal no Brasil. Rio de Janeiro, RJ: IBGE, 2011.

23. Alves $C$, Veiga S, Souza T. Dislipidemia e risco de doença cardiovascular em crianças e adolescentes com diabetes melito tipo1. Rev Paul Pediatria. 2007;25:82-9.

24. Jose LOS, Cardoso-Dermatini AA, Liberatore Junior RDR, et al. Clinical and laboratory profile of pediatric and adolescent patients with type 1 diabetes. J Pediatr. 2009:85:490-4.

25. Fröhlich-Reiterer EE, Rosenbauer J, Bechtold-DallaPozza S, Diabetes mellitus and Obesity. Predictors of increasing BMI during the course of diabetes in children and adolescents with type 1 diabetes: data from the German/Austrian DPV multicentre survey. Arch Dis Child. 2014;99:738-43.

26. Patton SR. Adherence to diet in youth with type 1 diabetes. J Am Diet Assoc. 2011;111:550-5.

27. Meissner T, Wolf J, Kersting M, et al. Carbohydrate intake in relation to BMI, $\mathrm{HbA1C}$ and lipid profile in children and adolescents with type 1 diabetes. Clin Nutr. 2014:33:75-8.

28. Mehta SN, Haynie DL, Higgins LA, et al. Emphasis on carbohydrates may negatively influence dietary patterns in youth with type 1 diabetes. Diabetes Care. 2009;32:2174-6.

29. Davison KA, Negrato CA, Cobas R, et al. Relationship between adherence to diet, glycemic control and cardiovascular risk factors in patients with type 1 diabetes: a nationwide survey in Brazil. Nutr J. 2014;7:13-9.

\section{Submit your next manuscript to BioMed Central and we will help you at every step:}

- We accept pre-submission inquiries

- Our selector tool helps you to find the most relevant journal

- We provide round the clock customer support

- Convenient online submission

- Thorough peer review

- Inclusion in PubMed and all major indexing services

- Maximum visibility for your research

Submit your manuscript at www.biomedcentral.com/submit
() Biomed Central 